\title{
Dilemmas of Neglected Humanitarian Crises
}

\author{
Michael VanRooyen, MD, MPH, FACEP, and Peter Walker, PhD
}

$\mathrm{I}$ n January 2007 Doctors Without Borders (Medécins Sans Frontières) published their annual list of the top 10 most underreported humanitarian stories of $2006 .^{1}$ This report is based on independently tracked media coverage of specific crises. ${ }^{2}$ In its World Disasters Report 2006, the International Federation of Red Cross and Red Crescent Societies reports on "neglected crises" such as those in Malawi, Guatemala, and Nepal, as well as on global inequities in humanitarian response to disasters that are less well publicized. ${ }^{3}$ Other United Nations and donor organizations rank their choices for the most forgotten humanitarian events. ${ }^{4,5}$ All of these reports draw attention to the worst disconnects between what the humanitarian community should do and does do in its mission to treat all victims of crisis in an impartial way.

Although no list adequately reflects the totality of the deep neglect and political, social and economic vulnerability that characterizes these crises, the countries that reappear yearly as systematically neglected are Democratic Republic of Congo (DRC), Chechnya, Colombia, Somalia, Nepal, Ethiopia, Sri Lanka, and northern Uganda. Iraq, which once enjoyed the health indices of a developed country, has continually slipped under the ravages of war and a level of ongoing insecurity that prevents its people from receiving the international assistance they deserve. In all conflict-related disasters, the civilian consequences of war-displacement, deprivation, and destruction of health services-have far exceeded the direct effects experienced by the combatants. Extreme poverty, the persistence of malaria, despite global initiatives to the contrary, and worsening gender-based violence have become sinister reminders of the systematic decay that these societies face during and long after the shooting and bombing have stopped.

Despite the significant international interest in large-scale natural disasters and catastrophic humanitarian emergencies precipitated by war, most humanitarian emergencies attract neither media coverage nor public or donor attention. Funding remains inadequate, and political attention is superficial at best. These forgotten crises highlight the inadequacies and underlying dilemmas that the global disaster community faces. The major question remains: How does the international aid community make policymakers, the press, and the public aware of the profound needs of regions affected by conflict and economic collapse?

At the heart of each and every crisis since the first international humanitarian response to the Lisbon earthquake of
$1755^{6}$ is a set of fundamental contradicting positions that continue to plague humanitarian action. First is the notion that crises and disasters are inherently unpredictable and outside our control. Almost all of the funding for humanitarian response is retrospective: the disaster happens, appeals are made, funds are raised, and relief operations are mounted. Imagine the consequences of operating a local fire service, let alone an international crisis relief system, on this basis. Second, there are 3 very different competing agendas that are bundled under the mantle of humanitarianism: the agenda of compassion, which seeks to address suffering here and now, but does not address root causes; the agenda of change, which seeks to alleviate suffering and change the system that caused the suffering; and the agenda of containment, which sees crises as threats to stability, security, and progress. These competing approaches create very different relationships between the assisting agency, the victims of the disaster, and its perpetrators. Humanitarianism today tries to but cannot be all things to all people.

Aid organizations, international media, and the international donor community evaluate, in their own idiosyncratic ways, the ongoing suffering that affects millions of poor and disaffected people. Partly because of this, aid coverage is inequitable and rarely based on reliable estimates of need or of proven best practices. ${ }^{7}$ Funding levels, for example, were 50 times higher for the people displaced by the 2004 Southeast Asia tsunami than for their counterparts in Chad and Niger, where the human needs were considerably greater. ${ }^{7}$ There remains a tremendous need to reliably measure the human impact of crises and quantify the needs of the affected populations.

The consequences of anecdotal information about crises can be grave. In February 2000 the New York Times reported on "Africa's first world war" in the DRC, estimating a death toll of 100,000 for the entire country. ${ }^{8}$ Between 2000 and 2004 the International Rescue Committee conducted a series of mortality studies to quantify the excess mortality in the DRC due to the conflict. The first study estimated 1.7 million excess deaths, and, for a brief time, focused long-overdue attention on the Great Lakes region. Follow-up studies through April 2004 have indicated a total of 3.9 million excess deaths. ${ }^{9}$ These surveys provided the data that ultimately led to a $45 \%$ increase in the funding for the DRC, which is now recognized as the deadliest war since World War II. 
In the article "Measuring Humanitarian Emergencies" in this issue, Richard Garfield, a widely known scholar on war mortality, highlights the necessity to use available data sources to prioritize humanitarian needs in countries affected by war. Garfield describes a cumulative summary measure to quantify humanitarian need, but appropriately reports that measuring the civilian excess mortality is by far a more difficult issue, and the only countries with methodologically sound estimates of mortality are Sudan (specifically, Darfur), DRC, and Iraq. Using combined data sources may be of use for combatant deaths, but it falls short of appropriately quantifying civilian deaths.

The responsibility for demonstrating evidence, therefore, remains in the hands of the organizations working in the field and the donors who require and fund data-driven interventions. Systematically addressing humanitarian needs across the world will be accomplished only if agencies become more evidence driven, if funding is provided in advance, and if coordination between nongovernmental organizations, governmental agencies, and funders becomes the expected norm. Media coverage and public perception can be powerful tools for mobilizing extra resources, but just as we no longer fund our schools and military this way, we should no longer rely on media reports to quantify need, or rely on public response to media to mobilize aid funding.

The challenge of disaster medicine is to understand the dynamics of conflict and disaster, evaluate the effects on vulnerable populations through field evidence, recognize those crises that do not receive proportional public attention, and seek ways to intervene based on demonstrated need and proven best practices. The needs of populations affected by disasters and crises must be quantified and we, as the response community, must be held accountable for responding appropriately. Ultimately, the evidence may help us challenge and change the political and economic systems that allow these crises to happen.

\section{About the Authors}

Dr VanRooyen is the director of the Division of International Health and Humanitarian Programs, Department of Emergency Medicine, Brigham and Women's Hospital, and the co-director of the Harvard Humanitarian Initiative. Dr Walker is Director of the Feinstein International Famine Center, Tufts University.

Address correspondence and reprint requests to Michael VanRooyen, MD, MPH, FACEP, Department of Emergency Medicine, Brigham and Women's Hospital, 75 Francis St, Boston, MA 02115 (e-mail: mvanrooyen@partners.org).

Received and accepted for publication August 15, 2007.

ISSN: 1935-7893 (C) 2007 by the American Medical Association and Lippincott Williams \& Wilkins.

DOI: 10.1097/DMP.0b013e318158859a

\section{REFERENCES}

1. Top 10 most underreported humanitarian stories of 2006. www.doctorswith outborders.org/publications/reports/2007/top10. Accessed February 6, 2007.

2. Tyndall Report. http://tyndallreport.com.

3. Walter J. World Disasters Report 2006: Focus on Neglected Crises. International Federation of Red Cross and Red Crescent Societies. Bloomfield, CT: Kumarian Press; 2007.

4. United Nations Office for the Coordination of Humanitarian Affairs. Review of OCHA Emergency Response Funds (ERFs). January 2007. http:// www.goodhumanitariandonorship.org/emergency $\% 20$ response $\% 20$ funds \%20final\%20review\%20report\%20Jan\%202007.pdf. Accessed October 12, 2007.

5. European Commission Humanitarian Aid. The Shadow of Forgotten Crises. European Commissioner's Directorate-General for Humanitarian Aid (ECHO). http://ec.europa.eu/echo/pdf_files/leaflets/forgotten_crises_en. pdf. Accessed October 12, 2007.

6. de Vattel E. The Law of Nations, Vol 2;1758:136.

7. Burnham G, Lafta R, Doocy S, Roberts L. Mortality after the 2003 invasion of Iraq: a cross-sectional cluster sample survey. Lancet. 2006; 368:1421-1428.

8. Fisher I, Onishi N, Swarns RL, Harden B, Cowell A. Chaos in Congo: a primer. Many armies ravage rich land in the "first world war" of Africa. New York Times. Published February 6, 2000. http://query.nytimes.com/gst/ fullpage. html?res=9D07E0D61 F3FF935A35751C0A9669C8B63. Accessed October 12, 2007.

9. Coghlan B, Brennan R, Ngoy P, et al. Mortality in the Democratic Republic of Congo: a nationwide survey. Lancet. 2006;367:44-51. 